\title{
Association of a genetic variant (rs689466) of Cyclooxygenase-2 gene with chronic periodontitis in a sample of Iraqi population
}

\author{
Suha A. Dahash, B.D.S.(1) \\ Maha Sh. Mahmood, B.D.S, M.Sc. ${ }^{(2)}$
}

\begin{abstract}
Background: periodontitis is a chronic inflammatory disease causing destruction of the tooth supporting structures, initiated by dental plaque and modified by environmental and genetic risk factors. Cyclooxygenase-2 (COX-2) enzyme is responsible for the production of prostaglandin E2, an important mediator in the chronic periodontitis (CP) pathogenesis. Polymorphisms in COX-2 gene have linked to CP in different populations.

Aim: To study the association between Cyclooxygenase-2 single nucleotide polymorphism rs689466 (-1195A/G SNP) and chronic periodontitis in a sample of Iraqi population.

Methods: One hundred Iraqi subjects divided into two groups: case group consisted of $70 \mathrm{CP}$ patient ( 35 males and 35 females) with age range 30-55 years, and control group consisted of 30 racially matched healthy subjects ( 15 males and 15 females) with age range 30-50 years. Clinical periodontal parameters including plaque index (PLI), gingival index $(\mathrm{Gl})$, bleeding on probing (BOP), probing pocket depth (PPD) and clinical attachment level (CAL) were recoded for all participants. $3 \mathrm{ml}$ of venous blood was collected from each participant for isolating genomic DNA. Genotyping of the rs689466 in COX-2 gene was performed using polymerase chain reaction-restriction fragment length polymorphism (PCR-RFLP) method.

Results: The frequency of $G$ allele carriers was significantly more prevalent in the case group compared to control group $(P=0.041)$, and allele $G$ was associated with greater susceptibility for chronic periodontitis compared to allele $\mathrm{A}(\mathrm{OR}=1.4)$.

Conclusion: COX-2 (rs689466) polymorphism may be associated with increased chronic periodontitis susceptibility. Key words: chronic periodontitis, cyclooxygenase-2, rs689466 polymorphism. (Received: 10/8/2018; Accepted: 4/9/2018)
\end{abstract}

\section{INTRODUCTION}

Chronic periodontitis (CP) is a complex, multifactorial inflammatory disease of the tooth supporting tissues leading to gradual irreversible tissue destruction and may eventually lead to tooth loss ${ }^{(\mathbf{1})}$. The primary factor that initiates and maintains periodontal inflammation is the dental plaque biofilm that forms on teeth surfaces in the absence of oral hygiene ${ }^{(2)}$.

Periodontitis develops from a pre-existing gingivitis which is reversible gingival inflammation. Individuals are not equally susceptible to periodontitis, in other words; not all cases of gingivitis progress to periodontitis in the presence of plaque deposits ${ }^{(3)}$. The inflammatory response is responsible for most of the tissue destruction in periodontitis. Therefore, the nature of the host inflammatory-immune response is the major determinant of host susceptibility (4). Susceptible individuals in whom gingivitis rapidly progress to periodontitis have a hyper inflammatory response characterized by increased production of proinflammatory mediators and oxidative stress ${ }^{(5-7)}$.

\footnotetext{
1. Master student, College of dentistry, University of Tikrit.

2. Professor, Department of periodontics, College of dentistry, University of Baghdad.
}

Many environmental and genetic factors influence the inflammatory response and the interaction of these factors determine whether the individual is susceptible to periodontitis or not ${ }^{\mathbf{( 8 )}}$.

Identification of the risk factors involved in the pathogenesis of periodontitis is important for better disease diagnosis and management ${ }^{(9)}$.

Periodontitis has been shown to have an inherited basis of about 50\%, meaning that genetic factors play an important role in disease susceptibility ${ }^{(10)}$. Genetic polymorphism in the molecules involved in periodontitis pathogenesis have been linked to increased risk for periodontitis in certain populations $(\mathbf{1 1}, \mathbf{1 2 )}$.

Cyclooxygenase-2 (COX-2) enzyme is one of the most effective mediators in the pathogenesis of periodontitis via converting arachidonic acid to prostaglandins ${ }^{(\mathbf{1 3})}$, it is the inducible form of the two cyclooxygenase isoforms (COX-1 and COX2) ${ }^{(14)}$. Bacterial endotoxins and proinflammatory cytokines stimulate COX-2 expression which in turn increases the production of prostaglandin E2 (PGE2) in the periodontal tissues ${ }^{(\mathbf{1 5})}$.

PGE2 causes more inflammation, tissue destruction and bone resorption. COX-2 expression is increased in periodontitis (16). Polymorphisms (most commonly single nucleotide polymorphisms (SNPs)) in the COX-2 
gene may affect gene expression rate and thus periodontitis susceptibility ${ }^{(17)}$.

SNPs in the COX-2 gene that have been linked to periodontitis susceptibility include rs689466, rs20417 and rs5275 (18)

In the present study we genotyped a sample of Iraqi population for rs689466 (-1195AG) SNP of COX-2 and tested the association of this SNP with chronic periodontitis.

\section{MATERIALS AND METHODS}

Study design and subjects:

This case-control study consisted of 100 Iraqi subjects of similar ethnic backgrounds recruited from the department of periodontics, college of Dentistry/University of Baghdad and the Iraqi national blood bank during the period from October 2017 to January 2018. Informed consent was obtained from each participant, and a questionnaire was used to record the background information, dental and medical histories of the participants.

Subjects were divided into two groups: control group (30 periodontally healthy subjects) and chronic periodontitis group (70 CP patients)

Criteria of the international classification of periodontal diseases and condition were used for diagnosing chronic periodontitis patients ${ }^{(19)}$.

Ethical approval was obtained from the ethical committee of the college of Dentistry/University of Baghdad.

\section{Clinical periodontal examination:}

Periodontal status of all the participants was examined by the same examiner using UNC-15 periodontal probe and the following periodontal parameters were recorded: plaque index, gingival index, bleeding on probing, probing pocket depth and clinical attachment level.

Blood sample collection and DNA isolation:

$3 \mathrm{ml}$ of the venous blood was collected in ethylene diamine tetra acetic acid (EDTA) tube using venipuncture method. DNA was isolated from the whole blood samples using gSYNCTM DNA extraction kit (Geneaid,Taiwan) and following the manufacturer's instructions. DNA samples were quantified by using a Nano-drop spectrophotometer then stored at $-70^{\circ} \mathrm{C}$.

Genotyping of COX-2 rs689466 polymorphism using polymerase chain reaction-restriction fragment length polymorphism (PCR-RFLP).

Polymerase chain reaction (PCR):

PCR was performed using a ready to use mixture (AccuPower® PCR PreMix from Bioneer/ Korea) which is supplied in $0.2 \mathrm{ml}$ tubes, each tube contains Taq polymerase (1U), Deoxynucleoside triphosphates (dNTPs) each $250 \mu \mathrm{M}, 1.5 \mathrm{mM} \mathrm{MgCl} 2$, Stabilizer and tracking dye. DNA sample and primers were added to the contents of the PCR PreMix tubes according to the manufacturer's instructions, then the tubes were transferred to a thermal cycler to complete the PCR according to the following program: initial denaturation at $95^{\circ} \mathrm{C}$ for 5 minutes, $30 \mathrm{PCR}$ cycles consisting of denaturation at $95^{\circ} \mathrm{C}$ for 30 seconds, annealing at $58^{\circ} \mathrm{C}$ for 45 seconds and extension at $72^{\circ} \mathrm{C}$ for 45 seconds followed by final extension at $72^{\circ} \mathrm{C}$ for 5 minutes. The following primers were used: forward primer 5'ccetgagcactacccatgat 3 ' and reverse primer 5 ' ccctgagcactacccatgat 3 , (17).

The anticipated PCR product (273bp) was visualized using agarose gel electrophoresis on a $1.5 \%$ gel concentration captured under UV light (figure 1).

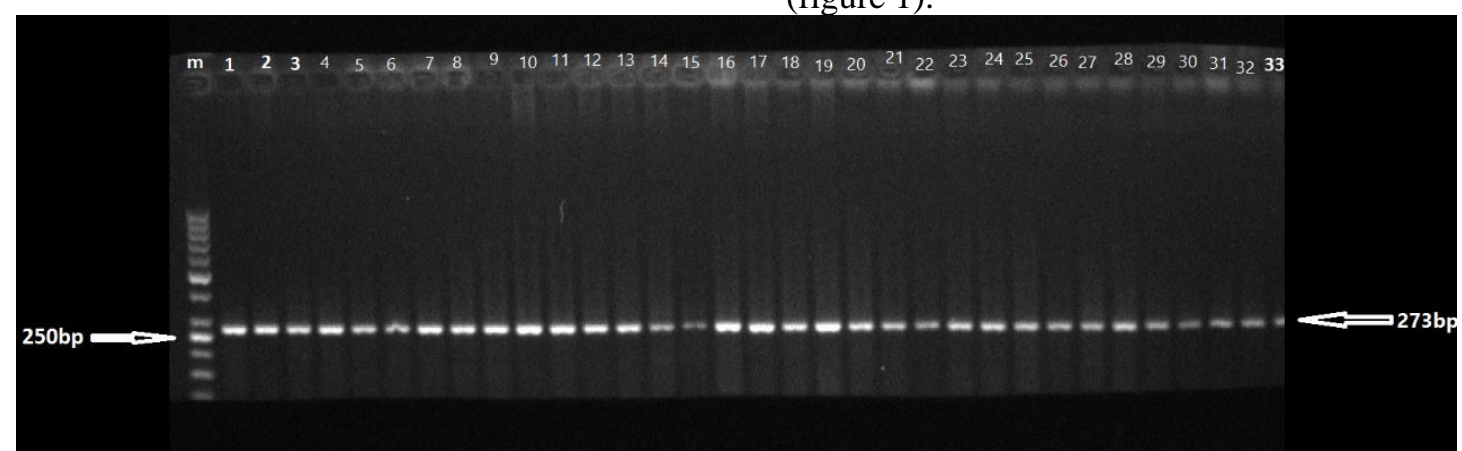

Figure 1: Results of the agarose gel electrophoresis of the PCR product for samples 1 to 33 ; m, DNA marker.

\section{Restriction fragment length polymorphism (RFLP):}

Pvull enzyme (SibEnzyme, Russia) was used for digesting the PCR product in order to produce fragments of different lengths to differentiate between different genotypes of rs689466 (-
$1195 \mathrm{~A} / \mathrm{G}$ SNP). In the presence of allele $\mathrm{G}$ at the position -1195 , Pvull enzyme cuts the 273bp PCR product into two fragments $(220 b p+53 b p)$, while in the absence of allele A the enzyme couldn't cut, thus the $273 \mathrm{bp}$ fragment remains the same. 
$10 \mu \mathrm{l}$ the PCR product of each sample was mixed with $1 \mu l$ of the Pvull enzyme, $2 \mu l$ of the SE Buffer, $1 \mu \mathrm{l}$ of the BSA and $1 \mu \mathrm{l}$ of the deionized distilled water. Then incubated in a thermal cycler at $37^{\circ} \mathrm{C}$ for 3 hours. The digestion product was separated by agarose gel electrophoresis using 3\% gel concentration and visualized under UV light. The three genotypes were differentiated according to the band size. 273bp band indicated AA genotype, 220bp band indicated GG genotype and the presence of both $220 \mathrm{bp}$ and 273bp bands indicated AG genotype. 53bp was not visible. (Figure 2).

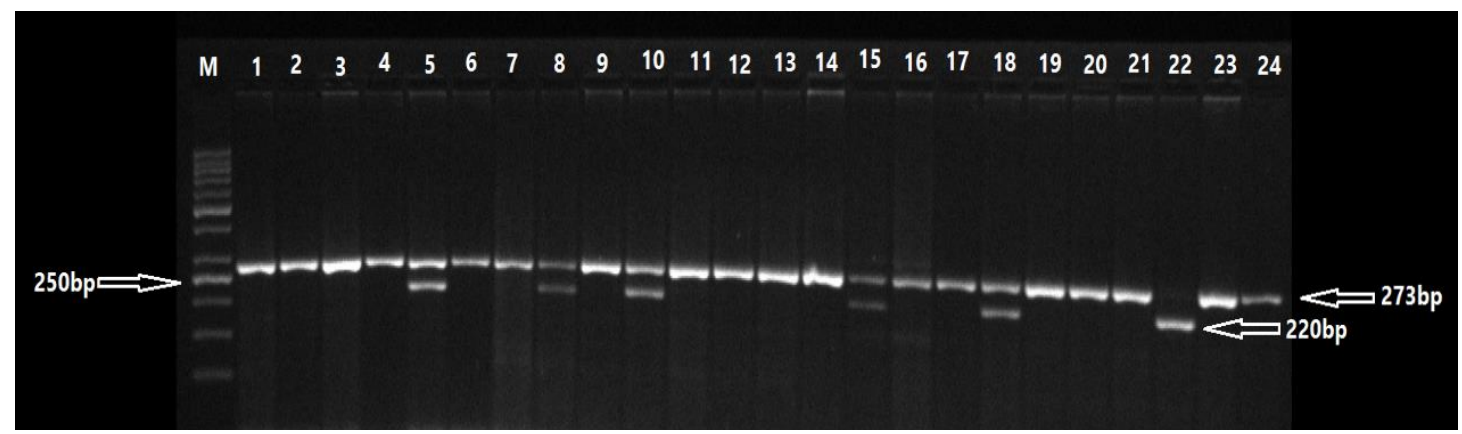

Figure 2: Agarose gel electrophoresis of restriction digestion product for samples (1-24). M, DNA marker; 273bp, AA genotype; 220bp, GG genotype; 273+220, AG genotype.

\section{Statistical analysis}

The statistical analysis system (SAS) program was used to perform statistical analysis. Descriptive statistics included: number, percentage, range, mean and standard deviation. $\mathrm{t}-$ test was used to compare between means and Chisquare to compare between percentages and genotype distributions. Results were considered significant when the probability $\mathrm{P} \leq 0.05$. Odds ratio (OR) was used to express the association of genotypes with disease risk. $\mathrm{OR}=1$ indicates no association, $\mathrm{OR}<1$ indicates reduced risk and $\mathrm{OR}>1$ indicates increased risk.

\section{RESULTS}

Characteristics of the study subjects (CP group and control group) are given in table 1 . The mean age $( \pm$ SD) for the control group was 42.03 $( \pm 5.70)$, and for CP group was $45.86( \pm 7.12)$. Male: female number was $15: 15$ in the control group and 35:35 in the CP cases.

Table 1: characteristics of study subjects

\begin{tabular}{|c|c|c|c|}
\hline \multicolumn{4}{|c|}{ Characteristics of controls and CP cases } \\
\hline \multirow{3}{*}{ Age } & Range & Control group(n=30) & CP group(n=70) \\
\cline { 2 - 4 } & Mean $( \pm$ SD) & $30-50$ & $30-55$ \\
\hline \multirow{2}{*}{ Gender } & Male no (\%) & $42.03( \pm 5.70)$ & $45.86( \pm 7.12)$ \\
\cline { 2 - 4 } & Female no (\%) & $15(50 \%)$ & $35(50 \%)$ \\
\hline
\end{tabular}

Table 2 shows the clinical periodontal parameters. The difference in the PLI and GI was significant between cases and controls $(\mathrm{p}=0.00146$ and 0.0016 for PLI and GI respectively). The percentage of bleeding sites (BOP score 1) in the CP group was $61.71 \%$. The mean Probing pocket depth (PPD) $( \pm \mathrm{SD})$ in the $\mathrm{CP}$ group was $3.094( \pm 0.642)$, and the mean clinical attachment level (CAL) $( \pm \mathrm{SD})$ was 4.33( \pm 0.913$)$.

Table 2: Clinical periodontal parameters

\begin{tabular}{|l|l|l|l|}
\hline & Control group $(\mathrm{n}=30)$ & CP group $(\mathrm{n}=70)$ & P-value \\
\hline Mean PLI $( \pm \mathrm{SD})$ & $0.827( \pm 0.228)$ & $1.979( \pm 0.245)$ & 0.00146 \\
\hline Mean GI $( \pm$ SD) & $0.631( \pm 0.158)$ & $1.632( \pm 0.298)$ & 0.0016 \\
\hline BOP score 1 $(\%)$ & --- & $61.71 \%$ & --- \\
\hline Mean PPD $( \pm$ SD) & --- & $3.094 \mathrm{~mm}( \pm 0.642)$ & --- \\
\hline Mean CAL $( \pm$ SD) & --- & $4.33 \mathrm{~mm}( \pm 0.913)$ & --- \\
\hline
\end{tabular}


Table 3 shows COX-2 rs689466 genotypes and alleles and their prevalence in the study subjects. $74 \%$ of the people were AA homozygous, $23 \%$ were AG heterozygous and $3 \%$ GG homozygous.
The dominant model (combining AG+GG in one group called allele $\mathrm{G}$ carriers) was used.

Table 3: Distribution of COX-2 rs689466 genotypes and alleles in the study population.

\begin{tabular}{|c|c|c|}
\hline Genotypes & Frequency in the study population & \multirow{2}{*}{ Total } \\
\hline AA homozygous & $74(74 \%)$ & \multirow{2}{*}{$\mathrm{n}=100$} \\
\hline AG heterozygous & $23(23 \%)$ & \\
\hline GG homozygous & $3(3 \%)$ & \\
\hline Allele G carriers (AG+GG) & $26(26 \%)$ & \multirow{2}{*}{$2 \mathrm{n}=200$} \\
\hline Alleles & $171(85.5 \%)$ & \\
\hline A (Wild) & $29(14.5 \%)$ & \\
\hline G (Mutant) & &
\end{tabular}

Distribution of the COX-2 rs689466 genotypes and alleles in CP cases and controls is illustrated in table 4. AA homozygous was significantly higher in the control group compared to $\mathrm{CP}$ group $(\mathrm{P}=0.047)$. The dominant model $(\mathrm{AG}+\mathrm{GG})$ revealed that allele $G$ carriers were significantly more prevalent in the $\mathrm{CP}$ cases compared to controls (0.041), and possess greater risk for disease as indicated by elevated odd ratio (1.6).

Table 4: Distribution of COX-2 rs689466 genotypes and allele frequency between controls and chronic periodontitis cases.

\begin{tabular}{|c|c|c|c|c|c|}
\hline \multicolumn{2}{|c|}{ COX-2 rs689466 } & Controls & CP cases & OR & p-value \\
\hline \multicolumn{2}{|c|}{ Genotypes } & $\mathbf{n = 3 0}$ & $\mathbf{n = 7 0}$ & & \\
\hline AA & No $(\%)$ & $24(80 \%)$ & $50(71.43 \%)$ & 0.625 & 0.047 \\
\hline (AG+GG) & No $(\%)$ & $6(20 \%)$ & $20(28.57 \%)$ & 1.6 & 0.041 \\
\hline \multicolumn{2}{|c|}{ Allele frequency } & $\mathbf{2 n = 6 0}$ & $\mathbf{2 n = 1 4 0}$ & & \\
\hline A & No $(\%)$ & $53(88.33 \%)$ & $118(84.29 \%)$ & 0.708 & 0.093 \\
\hline G & No $(\%)$ & $7(11.67 \%)$ & $22(15.71 \%)$ & 1.411 & 0.1447 \\
\hline
\end{tabular}

Table 5 shows the distribution of the COX-2 rs689466 genotypes and alleles between males and females. The prevalence of AA genotype was equal for both males and females $(74 \%, \mathrm{P}=1.00$ : $\mathrm{OR}=1)$. The prevalence of the mutant allele carriers $(\mathrm{AG}+\mathrm{GG})$ was also equal $(26 \%)$ in both genders with a non-significant difference in allele frequency between males and females (allele A frequency was $85 \%$ in males and $86 \%$ in females, $\mathrm{p}=0.887: \mathrm{OR}=0.92$. While allele $\mathrm{G}$ frequency was $15 \%$ in males and $14 \%$ in females, $\mathrm{p}=0.887$ : $\mathrm{OR}=1.08)$.

Table 5: Distribution of COX-2 rs689466 genotypes and allele frequency between males and females.

\begin{tabular}{|c|c|c|c|c|c|}
\hline \multicolumn{2}{|c|}{ COX-2 rs689466 } & Males & Females & OR & p-value \\
\hline \multicolumn{2}{|c|}{ Genotypes } & $\mathrm{n}=\mathbf{5 0}$ & $\mathrm{n}=\mathbf{5 0}$ & & \\
\hline AA & No $(\%)$ & $37(74 \%)$ & $37(74 \%)$ & 1 & 1.00 \\
\hline$(\mathrm{AG}+\mathrm{GG})$ & No $(\%)$ & $13(26 \%)$ & $13(26 \%)$ & 1 & 1.00 \\
\hline \multicolumn{2}{|c|}{ Allele frequency } & $2 n=100$ & $2 n=100$ & & \\
\hline A & No $(\%)$ & $85(85 \%)$ & $86(86 \%)$ & 0.92 & 0.887 \\
\hline $\mathrm{G}$ & No $(\%)$ & $15(15 \%)$ & $14(14 \%)$ & 1.08 & 0.887 \\
\hline
\end{tabular}

\section{DISCUSSION}

Periodontitis is a complex disease, although microbial dental plaque is the initiating factor, other environmental and genetic risk factors play important role in the pathogenesis. Identification of these risk factors is important for effective disease prevention and management ${ }^{(2)}$. As shown in (Table 2), the significant difference in the PLI and GI levels between controls and cases is explained by the fact that dental plaque is the primary cause of periodontal disease ${ }^{(2,11,20)}$.

In the pathogenesis of periodontitis, the induction of COX-2 by bacterial endotoxins and pro-inflammatory cytokines results in the production of increased amounts of prostaglandin E2 (PGE2) in periodontal tissues ${ }^{(15)}$. PGE2 is a potent inflammatory mediator and a stimulator of osteoclastogenesis and bone resorption (21, 22). 
Also it stimulates the production of matrix metalloproteinases causing further tissue destruction. It has been shown that the concentration of PGE2 in the gingival crevicular fluid is correlated with periodontal disease severity and reduced after treatment. COX-2 is over expressed in periodontitis ${ }^{(16,23)}$, while the inhibition of COX-2 reduces the rate of bone resorption and periodontal disease progression (24). Variations in the COX-2 gene have been linked to many inflammatory and proliferative diseases. COX-2 gene polymorphisms may influence periodontitis susceptibility by influencing the host's inflammatory response. The most common type of genetic polymorphisms are the single nucleotide polymorphisms (SNPs) in which a single nucleotide at a specific point is substituted be another nucleotide (25). Three SNPs rs689466, rs20417 and rs5275 in the COX-2 gene have been reported to be associated with periodontitis risk in different populations. However, the results were inconsistent ${ }^{(\mathbf{1 2})}$. In the present study the COX-2 rs689466 was investigated in a sample of Iraqi population and tested for association with chronic periodontitis. This SNP has been previously investigated in Chinese, European, and North Indian populations ${ }^{(18,26-28)}$. The results of our study showed that the distribution of the SNP genotypes in the Iraqi population (Table 3) is different from genotype distributions of the same SNP in the previously mentioned populations. AA homozygous was the most prevalent genotype in both controls and cases. However, it was significantly more prevalent in controls compared to $\mathrm{CP}$ cases and associated with reduced disease risk, while allele $\mathrm{G}$ carriers were significantly more prevalent in $\mathrm{CP}$ group compared to controls and associated with higher disease risk as indicated by elevated odd ratio (Table 4). A comparison between males and females showed a nearly equal distribution of COX-2 rs689466 genotypes and alleles between males and females (Table 5) suggesting that gender specific genetic effect may not contribute to the overall periodontitis risk, this agrees with Michalowicz et al (10).

As a conclusion, this study revealed that the genetic variant (rs689466) in the promotor area of COX-2 gene may be associated with $\mathrm{CP}$ susceptibility in Iraqi population. However, the study should be replicated in a larger independent sample of similar racial background.

\section{REFERENCES}

1. Huang N, Gibson FC. Immuno-pathogenesis of Periodontal Disease: Current and Emerging
Paradigms. Current oral health reports. 2014;1(2):12432.

2. AlJehani YA. Risk Factors of Periodontal Disease: Review of the Literature. International Journal of Dentistry. 2014;2014:182513.

3. Van der Velden U, Abbas F, Armand S, Loos BG, Timmerman MF, Van der Weijden GA, et al. Java project on periodontal diseases. The natural development of periodontitis: risk factors, risk predictors and risk determinants. J Clin Periodontol. 2006; 33(8):540-8.

4. Pihlstrom BL, Michalowicz BS, Johnson NW. Periodontal diseases. Lancet (London, England). 2005; 366(9499):1809-20.

5. Kinane DF, Preshaw PM, Loos BG. Host-response: understanding the cellular and molecular mechanisms of host-microbial interactions--consensus of the Seventh European Workshop on Periodontology. J Clin Periodontol. 2011;38 Suppl 11:44-8.

6. Ali BT, Mahmood MS. Assessment of Salivary Total Antioxidants Capacity Levels of Patients with Chronic Periodontitis in Comparison to Healthy Control. Journal of baghdad college of dentistry 2018;30(1): 58-62.

7. Hamed MN, Ali BG. Serum Level of TNF- $\alpha$ and IL17 in Patient Have Chronic Periodontitis Associated Rheumatoid Arthritis. Journal of baghdad college of dentistry. 2017;29(1):104-10.

8. Shapira L, Wilensky A, Kinane DF. Effect of genetic variability on the inflammatory response to periodontal infection. J Clin Periodontol. 2005;32 Suppl 6:72-86.

9. Carinci F, Palmieri A, Girardi A, Cura F, Lauritano D. Genetic Risk Assessment of Periodontal Disease during Dental Treatments2015.

10. Michalowicz BS, Diehl SR, Gunsolley JC, Sparks BS, Brooks CN, Koertge TE, et al. Evidence of a substantial genetic basis for risk of adult periodontitis. J Periodontol. 2000;71(11):1699-707.

11. Banjar W, Alshammari MH. Genetic factors in pathogenesis of chronic periodontitis. Journal of Taibah University Medical Sciences. 2014;9(3):245-7.

12. da Silva MK, de Carvalho ACG, Alves EHP, da Silva FRP, Pessoa LDS, Vasconcelos DFP. Genetic Factors and the Risk of Periodontitis Development: Findings from a Systematic Review Composed of 13 Studies of Meta-Analysis with 71,531 Participants. Int J Dent. 2017;2017:1914073.

13. Noguchi K, Ishikawa I. The roles of cyclooxygenase-2 and prostaglandin E2 in periodontal disease. Periodontol 2000. 2007;43:85-101.

14. Smith WL, Urade Y, Jakobsson P-J. Enzymes of the Cyclooxygenase Pathways of Prostanoid Biosynthesis. Chemical Reviews. 2011;111(10):5821-65.

15. Båge T, Kats A, Lopez BS, Morgan G, Nilsson G, Burt I, et al. Expression of Prostaglandin E Synthases in Periodontitis: Immunolocalization and Cellular Regulation. The American Journal of Pathology. 2011;178(4):1676-88.

16. Lohinai Z, Stachlewitz R, Szekely A, Feher E, Dezsi L, Szabo C. Evidence for the expression of cyclooxygenase- 2 enzyme in periodontitis. Life sciences. 2001;70(3):279-90.

17. Zhang X, Miao X, Tan W, Ning B, Liu Z, Hong Y, et al. Identification of functional genetic variants in cyclooxygenase- 2 and their association with risk of 
esophageal cancer. Gastroenterology. 2005; 129(2): 565-76.

18. Daing A, Singh SV, Saimbi CS, Khan MA, Rath SK. Cyclooxygenase 2 gene polymorphisms and chronic periodontitis in a North Indian population: a pilot study. Journal of Periodontal \& Implant Science. 2012;42(5):151-7.

19. Armitage GC. Development of a Classification System for Periodontal Diseases and Conditions. Annals of periodontology. 1999;4(1):1-6.

20. Taba Jr M, Souza SLSd, Mariguela VC. Periodontal disease: a genetic perspective. Brazilian Oral Research. 2012;26:32-8.

21. Dziak R. Biochemical and molecular mediators of bone metabolism. Journal of periodontology. 1993;64(5 Suppl):407-15.

22. Salvi GE, Lang NP. Host response modulation in the management of periodontal diseases. J Clin Periodontol. 2005;32 Suppl 6:108-29.

23. Cai X, Li C, Du G, Cao Z. Protective effects of baicalin on ligature-induced periodontitis in rats. Journal of periodontal research. 2008;43(1):14-21.
24. Yen CA, Damoulis PD, Stark PC, Hibberd PL, Singh M, Papas AS. The effect of a selective cyclooxygenase-2 inhibitor (celecoxib) on chronic periodontitis. J Periodontol. 2008;79(1):104-13.

25. Schork NJ, Fallin D, Lanchbury JS. Single nucleotide polymorphisms and the future of genetic epidemiology. Clinical genetics. 2000;58(4):250-64.

26. Xie C-J, Xiao L-M, Fan W-H, Xuan D-Y, Zhang J-C. Common single nucleotide polymorphisms in cyclooxygenase-2 and risk of severe chronic periodontitis in a Chinese population. Journal of Clinical Periodontology. 2009;36(3):198-203.

27. Schaefer AS, Richter GM, Nothnagel M, Laine ML, Noack B, Glas J, et al. COX-2 is associated with periodontitis in Europeans. J Dent Res. 2010;89(4):384-8.

28. Prakash G, Umar M, Ajay S, Bali D, Upadhyay R, Gupta KK, et al. COX-2 gene polymorphisms and risk of chronic periodontitis: a case-control study and meta-analysis. Oral Diseases. 2015;21(1):38-45.

\section{الخلاصة الخة}

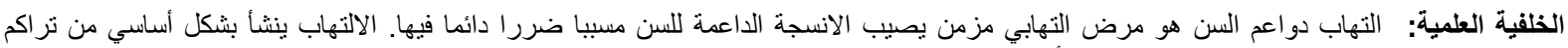

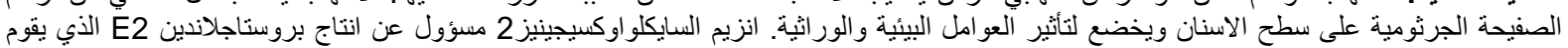

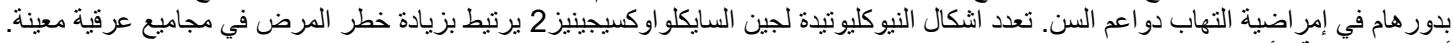

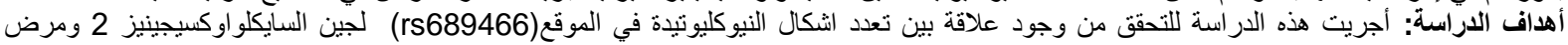

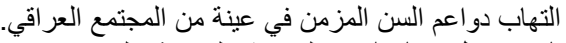

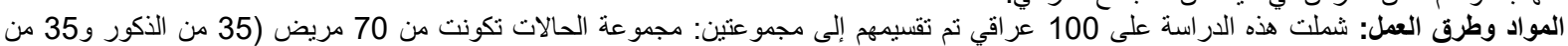

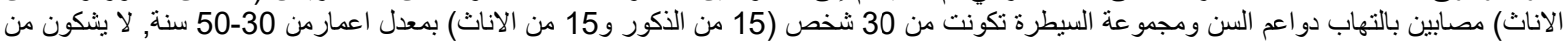

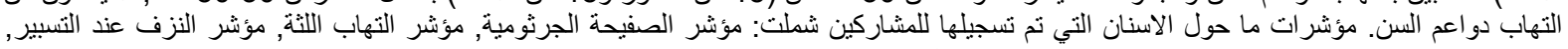

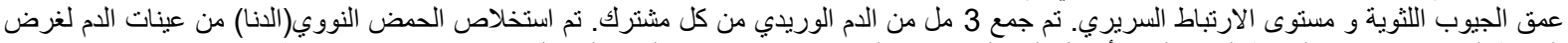
التنميط الجيني. تم إجر اء التتميط الجيني لتعدد أنثكال النيوكليوتيدة في الموقع(rs689466) لجين السايكلو اوكسيجينيز 2 باستخدام طريقة: Polymerase chain reaction-restriction fragment length polymorphism

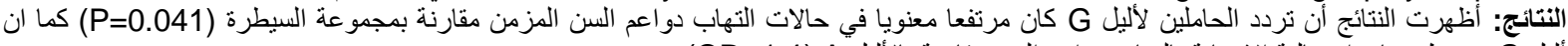

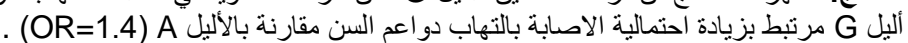

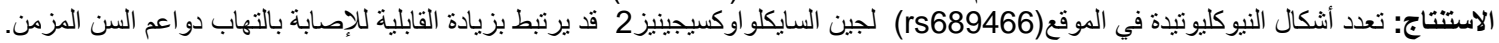

